\title{
Left atrial myxomas in childhood: Presentation with emboli-diagnosis by ultrasonics
}

\author{
R O N A L D B. PRIDIE 1
}

\author{
Royal Postgraduate Medical School, Hammersmith Hospital, and Harefield Hospital
}

\begin{abstract}
Three children with left atrial myxomas are described. All suffered major arterial occlusion with consequent permanent morbidity before the diagnosis was made and the tumour removed. Each child had had previous small embolic phenomena. In two, the diagnosis was made by ultrasound. In any child who has had an arterial embolus without obvious cause, a left atrial myxoma should be considered and looked for by an ultrasonic mitral echogram.
\end{abstract}

Left atrial myxomas have been described previously in 19 children aged 15 years or less (Jacobsthahl, 1900; Meyer, 1900; Schwarz, 1927; Goldberg, Glenn, Dotter, and Steinberg, 1952; Centeno, 1955; Gleason, 1955; Case report, 1957; Skanse, Berg, and Westfelt, 1959; Beanlands, Dolan, and Shane, 1960; Chao, Henry, and Rosenberg, 1960; Cumming and Finkel, 1961; Differding, Gardner, and Roe, 1961; Lelong et al., 1961; Wyler, Ruckli, and Weisser, 1965; Sterns, Eliot, Varco, and Edwards, 1966; Mazuria, Soboleva, and Semenov, 1967; Carile, Rutiloni, and Seganti, 1968; Marpole, Kloster, Bristow, and Griswold, 1969; Hauwaert, 1971).

Sixteen of these reports have appeared since the first attempt to remove such a tumour from a child in 1952 (Goldberg et al., 1952) and 15 since the first successful surgical removal of an atrial myxoma from an adult by Crafoord in 1955. Successful surgery has been accomplished in five of these children (Beanlands et al., 1960; Differding et al., 1961; Hauwaert, 1971; Lelong et al., 1961; Marpole et al., 1969). Only 2 of the 14 children whose history is adequately documented had no systemic emboli.

Three more children with left atrial myxomas are described. All had emboli. In two, the diagnosis was made on an ultrasonic mitral echogram. The increasing number of reports which have appeared in recent years suggests that atrial myxomas are perhaps not as uncommon in children as is sometimes thought and that this diagnosis should be considered in any child who presents with a systemic embolus. The diagnosis can be made accurately and atraumatically with ultrasound.

\section{CASE REPORTS}

CASE 1 Three years previously, at the age of 12, C.L. IIn receipt of a grant from the British Heart Foundation had been found on the bathroom floor with weakness of the left arm and left leg. Rapid recovery occurred but two months later the weakness of both limbs recurred and he was admitted to a paediatric unit where the house physician noted a systolic murmur. The ESR was $53 \mathrm{~mm} / \mathrm{hr}$ (Westergren).

Two months later a consultant orthopaedic surgeon saw him because of pains in both great toes. Good peripheral pulses were noted. After this he remained well for 18 months and then collapsed at school. Consciousness was not lost but he was confused and had pain in the feet for two days. Three months later he was referred to the local hospital because of faintness, vomiting, dysphagia, diplopia, and nasal speech. Two months afterwards he was seen by an ophthalmologist who found no double vision.

The lad, now 14 years old, was then seen by a psychiatrist who accepted that his symptoms were psychogenic in origin.

A year after this he presented with cellulitis of the right leg. Anterior and posterior tibial pulses were normal. The tibia was drilled but no pus was obtained. A non-haemolytic streptococcus was grown from the fluid. The leg deteriorated and an above-knee amputation was performed. The muscle of the amputated leg showed ischaemic changes. The right femoral pulse was noted to be weak. In a few days he developed a dry cough, fever, and tachycardia and his left arm and leg stump became cold, pulseless, and white. Embolectomy by Fogarty catheter produced firm clots from both the arm and the leg. These grew nonhaemolytic streptococci but were not examined histologically. Shortly after this he was transferred to Hammersmith Hospital with the comment that 'We have not located the source of his emboli or his septicaemia'. Examination on admission revealed a short systolic cardiac murmur and absent right femoral and left radial pulses. The electrocardiogram indicated left atrial hypertrophy. A left atrial myxoma was suspected from the history and confirmed on the night of his admission first by an ultrasonic mitral echogram (Fig. 1) and then by a pulmonary angiogram. The tumour was removed next morning by 
Mr. Paneth at the Brompton Hospital. This was followed by an uneventful recovery.

COMMENT Five patients with atrial myxomas and a septicaemia (all in adults) are recorded in the literature (Dick and Mullin, 1956; Permyakov, 1961; Rae, 1965; Mihailescu and Paraschiv-Dosius,

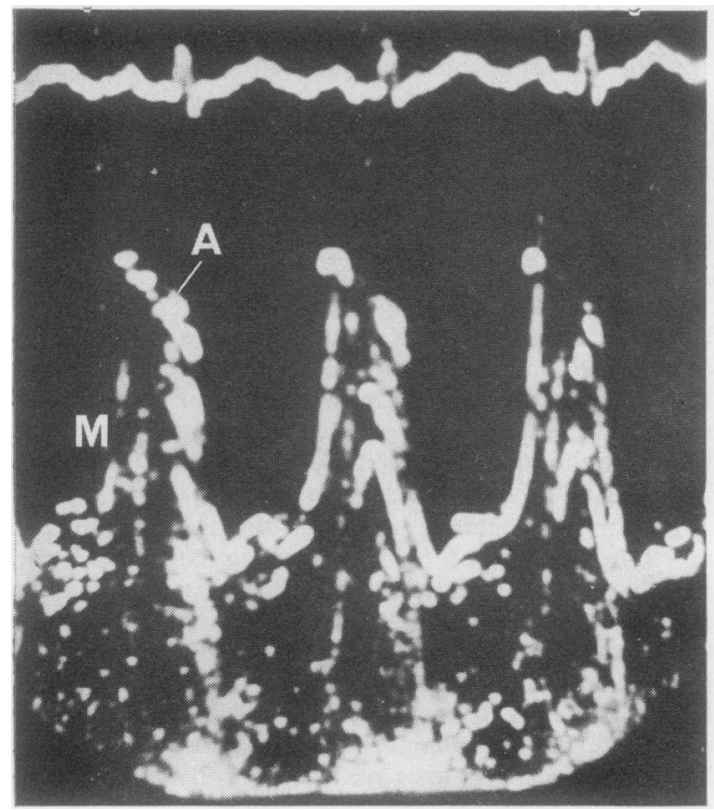

FIG. 1. Case 1. Ultrasonic mitral echogram showing multiple echoes $(M)$ behind that of the anterior cusp of the valve $(A)$.

1968; Malloch, Abbott, and Rapaport, 1970). A positive culture does not therefore rule out an atrial myxoma.

Histological examination of the amputated leg or of the embolus which was removed would have revealed the nature of the occlusion and have led to the diagnosis as it did in the case described by Beanlands et al. (1960).

CASE 2 R.H. aged $7 \frac{1}{2}$ was admitted to an eye hospital with dacryocystitis and found to have a haemoglobin of $59 \%$ and an ESR of $46 \mathrm{~mm} / \mathrm{hr}$ (Westergren). On discharge he was referred to a paediatric unit where the anaemia was treated with ferrous sulphate but six months later his haemoglobin was only $68 \%$. About this time he had an attack of pins and needles in the left leg which cleared spontaneously after three to four days. Two months later he had a similar but more painful attack which caused him to drag his foot and prevented him from sleeping. He attended the local casualty department, was given aspirin, and was reassured.
Five weeks later he fell from a $10 \mathrm{ft}(3 \mathrm{~m})$ wall. On landing he was unconscious, had urinated, and had a right hemiplegia. He was admitted to The London Hospital where he regained consciousness after four days. A right hemiplegia and hemianopia remained and speech was confined to 'Yes'. Carotid arteriography confirmed the neurosurgical clinical diagnosis of a middle cerebral artery occlusion.

He was then seen by a cardiologist who found mitral pansystolic and mid-diastolic murmurs and diagnosed an atrial myxoma, which was confirmed by angiography. The tumour was removed by Mr. Donald Ross at the National Heart Hospital. Despite a successful operation the child is educationally subnormal and has a speech defect and a residual hemiplegia.

COMMENT The episodes of paresthesiae in the foot were probably caused by emboli. Had he not had recurrent infections of the tear duct, the high ESR and anaemia might have led to the diagnosis of the myxoma before cerebral damage occurred.

CASE 3 M.S., a 7-year-old boy, was admitted to hospital because of a pyrexia which had not responded to one week's treatment with erythromycin. He had pains in the right leg and ankle, which has lasted longer and been more severe than similar pains in the same site which had attacked him intermittently during the previous year.

The only clinical abnormality noted on admission, apart from the raised temperature, was a pulse rate of $120 /$ minute. Proteinuria and microscopic haematuria were present and his ESR was $85 \mathrm{~mm} / \mathrm{hr}$ (Westergren). The blood urea was $43 \mathrm{mg} / 100 \mathrm{ml}$ and an intravenous pyelogram was normal. When seen by a cardiologist he was found to have an intermittent presystolic murmur and a loud first sound but auscultation was difficult because of tachycardia. Blood cultures were normal and it was recommended that he be treated with penicillin and salicylates.

One month after admission he had a five-minute episode of unconsciousness during which a facial palsy was noted. An ultrasonic mitral echogram was made two weeks later in order to assess the degree of mitral valve disease. This revealed the multiple echoes of a tumour behind the anterior mitral cusp in diastole (Fig. 2a, b) and a variable diastolic closure rate which indicated a varying degree of mitral obstruction.

Six days after this he had left chest pain and collapsed. An ECG showed first, complete atrioventricular block, then nodal rhythm, and finally sinus rhythm. Following this episode the left arm pulses and the peripheral leg pulses were impalpable. The serum aspartate aminotransferase was 97 units, the serum lactate dehydrogenase was 680 units, and the ECG showed changes of a posterior cardiac infarct. Four days later a pulmonary angiogram followed through to the left atrium revealed a space-occupying lesion there. A left atrial myxoma was subsequently removed by Mr. D. J. Waterston at the Hospital for Sick Children, Great Ormond Street, and cardiac 


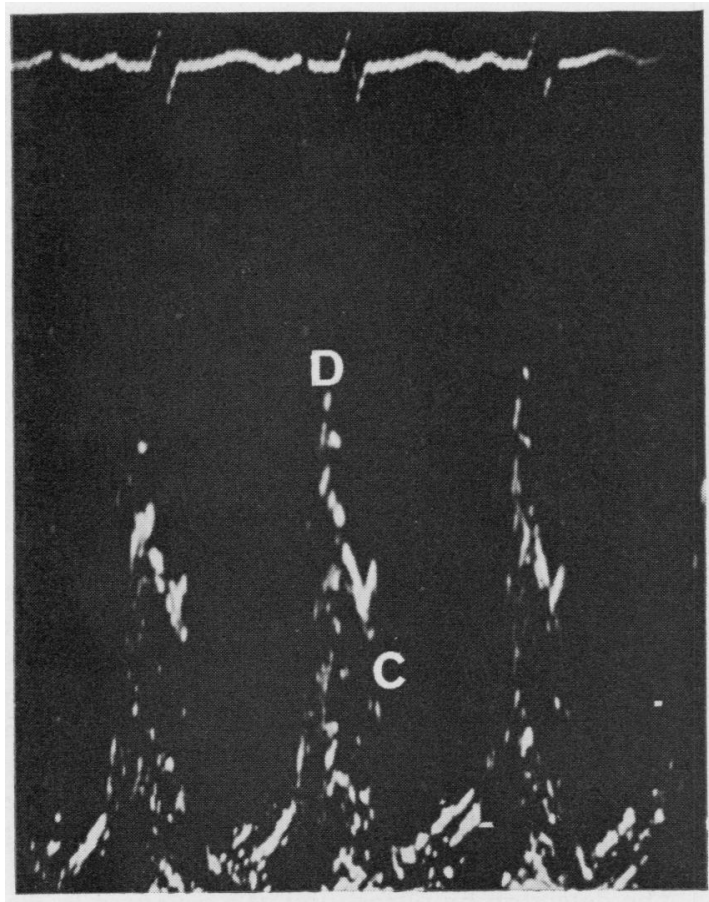

(a)

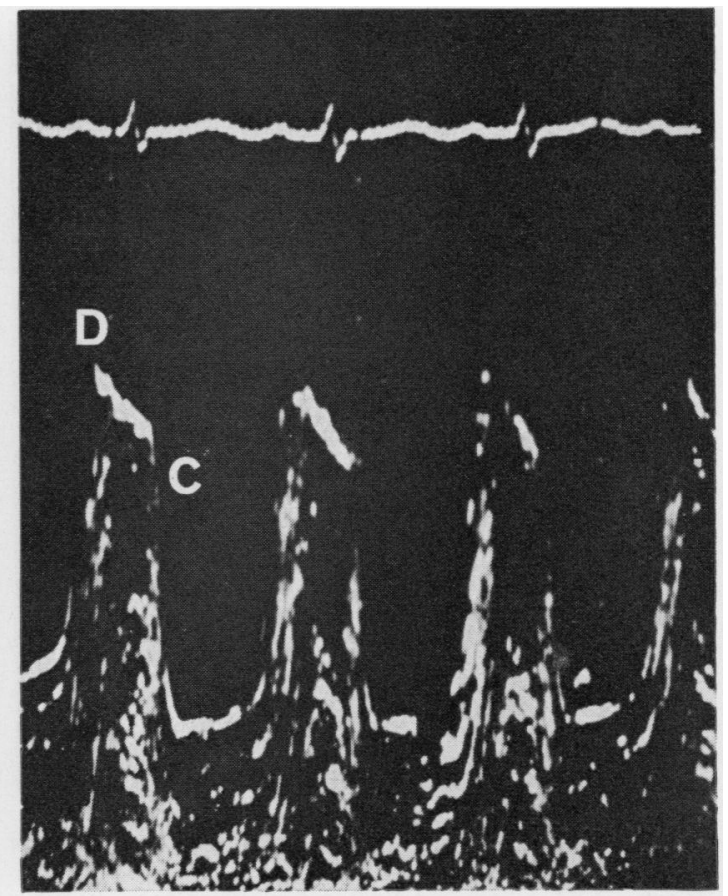

(b)

FIG. 2. Case 3. Echograms taken preoperatively showing multiple echoes behind the mitral cusp in diastole. (a) The diastolic closure rate indicated by the slope $D C$ is $75 \mathrm{~mm} / \mathrm{sec}$, which is within the normal range. (The dots are separated by $0.5 \mathrm{sec}$ horizontally and by $1 \mathrm{~cm}$ vertically.) rate is reduced, indicating mitral obstruction.

infarction was confirmed at operation which has been reported by Nicholls, Goodman, and Pridie (1971). The child made an uneventful recovery. The mitral echogram has subsequently shown no echoes behind the anterior mitral cusp (Fig. 3).

COMMENT Although this child is now quite well, the embolic episodes which occurred between the diagnosis by ultrasound and subsequent surgery emphasize the need to avoid delay in removing a myxoma once it has been diagnosed.

\section{DISCUSSION}

Although atrial myxomas are histologically benign, death will follow if they are not removed (Goodwin, 1963). This is because they give rise to emboli which occlude vital arteries. Such emboli rarely grow into secondary deposits so the condition can be cured completely by surgical excision of the tumour.

Left atrial myxomas may present as mitral stenosis (but often with varying heart murmurs) or subacute bacterial endocarditis with changing (b) Echogram taken 2 min later when the diastolic closure

heart murmurs, fever, high ESR, and embolic phenomena.

Mitral stenosis is uncommon in the paediatric age group (Keith, Rowe, and Vlad, 1967) and so is bacterial endocarditis. Only $4 \%$ of Cates' and Christie's (1951) series of 408 cases of bacterial endocarditis were under 15 years of age. Left atrial myxomas should therefore be considered whenever either of these diagnoses is suspected in a child.

Only one of these three children had clear evidence of heart disease when first examined by a cardiologist. The signs of mitral obstruction in case 2 had not been noted previously-admittedly by less experienced observers-but the intermittency of the murmurs is a feature of atrial myxoma. Absence of heart murmurs does not rule out this diagnosis, nor does a normal ESR. Emboli are rare in children. Atrial myxoma is therefore likely when an embolus occurs in a child whether or not there is obvious heart disease and especially if in sinus rhythm. 


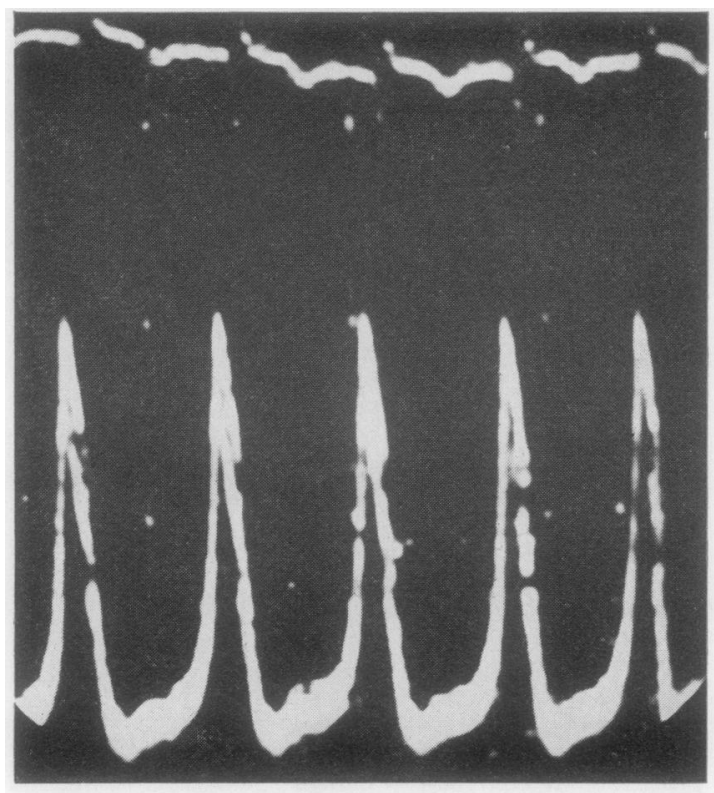

FIG. 3. Case 3. Postoperative echogram showing absence of echoes behind the valve.

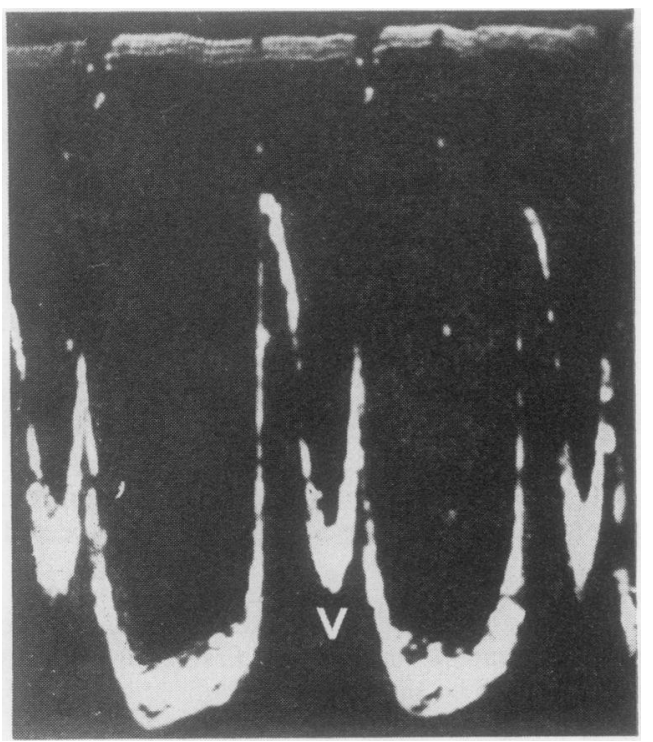

FIG. 4. Normal mitral echogram showing a clear area (v) below the valve in diastole.

The diagnosis of left atrial myxoma can be proved or disproved very simply in both adults and children by means of ultrasound.

DIAGNOSIS BY ULTRASOUND Reflected ultrasound has been used to record the movements of the mitral valve since Edler and Hertz described the method in 1954. Ultrasound waves are produced when electric impulses are applied to a piezoelectric transducer sited on the praecordium. The ultrasound can be reflected back from the anterior cusp of the mitral valve so as to fall again on the transducer and generate a secondary electric current. Both the primary and secondary currents are made to deflect the spot of an oscilloscope. The distance between the two deflections is proportional to the distance of the reflecting surface from the transducer.

Repetition of the impulses 2,000 times per second produces a continuous record of the mitral valve position.

In the normal subject, the mitral valve moves in the left ventricle (Fig. 4) with only blood behind it during diastole. When a left atrial myxoma is present it moves towards the left ventricle in diastole and comes to lie behind the anterior cusp of the mitral valve. Such tumours contain many interfaces which reflect ultrasound and produce multiple echoes behind that of the anterior mitral cusp echo where normally there are none.

The detection by ultrasound of a myxoma in the left atrium was first made by Effert and Domanig in 1959. Since that time, Wolfe, Popp, and Feigenbaum (1969) have described two cases, and Shattenberg (1968) and Popp and Harrison (1969) one each.

RELIABILITY OF METHOD A large series of patients with this uncommon condition is not available to enable the accuracy of this method of diagnosis to be assessed. Proven atrial myxomas in six patients examined personally by this method have $\exists$ each produced a positive echogram and no false positive has been seen in many hundreds of mitral echograms.

Theoretically it might be possible for a left atrial myxoma to remain entirely within the body of the atrium throughout the whole cardiac cycle and thus not produce the characteristic echoes behind $\mathcal{N}$ the anterior mitral cusp. Such a tumour would $N$ have to be small. The atrium is not intrinsically affected by the presence of a myxoma and sinus rhythm usually persists. The mitral obstruction is commonly intermittent and often not severe. This is exemplified in case 3 where in the first echogram $\cong$ the diastolic closure rate is normal (Fig. 2a) and in the second (Fig. 2b) the closure rate in diastole is reduced as in other forms of mitral obstruction. $\mathbb{D}$

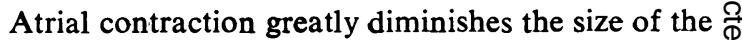
atrial cavity and can be expected to push the $\varrho$ 
tumour into the mitral ring where it will be revealed.

The atraumatic nature of this examination makes it very suitable for use in children. The apparatus can be taken to the bedside-even to another hospital, as in case 3-for it is portable and robust and can be transported in the boot of a small car.

It is a convenient and reliable diagnostic method for left atrial myxomas.

Dr. Celia Oakley, Dr. Lawson McDonald, and Dr. I. G. Wickes, under whose care these children were, are thanked for permission to publish details of their case histories.

Case 3 is reproduced from the Postgraduate Medical Journal (vol. 47, p. 804, 1971) with the permission of the authors and the editor.

The assistance of Susan Pridie with the bibliography is acknowledged gratefully.

\section{REFERENCES}

Beanlands, D. S., Dolan, F. G., and Shane, S. J. (1960). Myxoma of the left atrium-case report. Canad. med. Ass. J., 83, 715.

Carile, L., Rutiloni, C., and Seganti, A. (1968). Cardiac myxoma in children. Anatomo-clinical study. Minerva Pediat., 20, 1089.

Case report (1957). New Engl. J. Med., 256, 516.

Cates, J. E., and Christie, R. V. (1951). Subacute bacterial endocarditis-a review of 442 patients treated in 14 centres appointed by the Penicillin Trials Committee of the Medical Research Council. Quart. J. Med., 20, 93.

Centeno, P. A. (1955). Myxofibromia of the left atrium simulating rheumatic heart disease. Pediatrics, 16, 489.

Chao, D. H. C., Henry, M. G., and Rosenberg, H. S. (1960). Myxoma of the heart with internal carotid artery occlusion in a child. Neurology (Minneap.), 10, 418.

Crafoord, C. (1955). In Cardiovascular Surgery. Proceedings of the International Symposium on Cardiovascular Surgery held at Henry Ford Hospital, Detroit, Michigan, March 1955, ed. by C. R. Lam, p. 202. Saunders, Philadelphia.

Cumming, G. R., and Finkel, K. (1961). Intracardiac myxoma involving the right and left atria in a young patient. J. Pediat., 58, 559.

Dick, H. J., and Mullin, E. W. (1956). Myxoma of the heart complicated by bloodstream infection by Staphylococcus aureus and Candida parapsilosis. N.Y. St. J. Med., 56, 856.

Differding, J. T., Gardner, R. E., and Roe, B. B. (1961). Intracardiac myxomas with report of two unusual cases and successful removal. Circulation, 23, 929.

Edler, I., and Hertz, C. H. (1954). The use of ultrasound reflectoscope for the continuous recording of the movements of heart walls. Kungliga Fysiografiska Sällskapets i Lund Förshandlingar, 24, No. 5, p. 40.

Effert, S., and Domanig, E. (1959). The diagnosis of intraatrial tumours and thrombi by the ultrasonic echo method. Germ. med. Mth., 4, 1.
Gleason, I. O. (1955). Primary myxoma of the heart. A case simulating rheumatic and bacterial endocarditis. Cancer (Philad.), 8, 839.

Goldberg, H. P., Glenn, F., Dotter, C. T., and Steinberg, I. (1952). Myxoma of the left atrium-diagnosis made during life with operative and post-mortem findings. Circulation, 6, 762.

Goodwin, J. F. (1963). Diagnosis of left atrial myxoma. Lancet, 1, 464.

Hauwaert, L. G. Van der (1971). Cardiac tumours in infancy and childhood. Brit. Heart J., 33, 125.

Jacobsthahl, H. (1900). Cassuistische Mittheilungen. Virchows Arch. Path. Anat., 159, 351.

Keith, J. D., Rowe, R. D., and Vlad, P. (1967). Rheumatic fever and rheumatic heart disease. In: Heart Disease in Infancy and Childhood, 2nd edition, p. 902. Macmillan, London.

Lelong, M., Dubost, C., Canlorbe, P., Eccoifier, J., Vinh, L. T., Vassal, J., Jean, R., Benaim, P., Plainfosse, B., Piwnica, A., Blóndeau, P., and Rivron, J. (1961). Myxome de l'oscillitte gauche chez un enfant de 12 ans. Intervention, guérison. Bull. Soc. méd. Hôp. (Paris), 77, 797.

Malloch, C. I., Abbott, J. A., and Rapaport, E. (1970). Left atrial myxoma with bacteremia. Report of a case with a bifid systolic apical impulse. Amer.J. Cardiol., 25, 353.

Marpole, D. G. F., Kloster, F. E., Bristow, J. D., and Griswold, H. E. (1969). Atrial myxoma, a continuing diagnostic challenge. Amer. J. Cardiol., 23, 596.

Mazuria, A. V., Soboleva, N. I., and Semenov, B. N. (1967). Cardiac myxoma in children. Pediatriya, 46, No. 10, 50.

Meyer, G. (1900). Ein Myxom des linken Herzohrs: Beitrag zur Kenntniss der primären Herzgeschwülste. C. Georgi, Bonn.

Mihailescu, V. V., and Paraschiv-Dosius, L. H. (1968). Anatomo-clinical considerations on a case of atrial myxoma associated with bacterial endocarditis. Medicina interna (Buc.), 20, 361.

Nicholls, A. J. S., Goodman, M. A., and Pridie, R. B. (1971). Left atrial myxoma in a child diagnosed by ultra-sound. Postgrad. med. J., 47, 804.

Permyakov, N. K. (1961). Septic complications of myxoma of the heart. Klin. Med. (Russia), 39, 144.

Popp, R. L., and Harrison, D. C. (1969). Ultrasound for the diagnosis of atrial tumour. Ann. intern. Med., 71, 785.

Rae, A. (1965). Two patients with cardiac myxoma-one presenting as bacterial endocarditis, and one as congestive cardiac failure. Postgrad. med. J., 41, 644.

Schwarz, D. (1927). Uber die sogenannten Myxome des Herzens. Virchows Arch. path. Anat., 264, 747.

Shattenberg, T. T. (1968). Echocardiographic diagnosis of left atrial myxoma. Mayo Clin. Proc., 43, 620.

Skanse, B., Berg, N. O., and Westfelt, L. (1959). Atrial myxoma with Raynaud's phenomenon as the initial symptom. Acta med. scand., 164, 321.

Sterns, L. P., Eliot, R. S., Varco, R. L., and Edwards, J. E. (1966). Intracavitary cardiac neoplasms. A review of fifteen cases. Brit. Heart J., 28, 75.

Wolfe, S. B., Popp, R. L., and Feigenbaum, H. (1969). Diagnosis of atrial tumors by ultrasound. Circulation, 39, 615.

Wyler, F., Ruckli, A., and Weisser, K. (1965). Myxom des linken Vorhofes bei einem $8 \frac{1}{2}$ jährigen Mädchen. $Z$. Kinderheilk, 94, 51. 